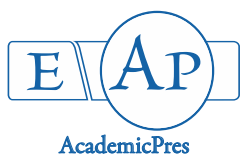

Eng W-H et al. (2021)

Notulae Scientia Biologicae

Volume 13, Issue 3, Article number 10995

DOI: $10.15835 /$ nsb13310995

Research Article

\title{
Cytogenetic, chromosome count optimization and automation of Neolamarckia cadamba (Rubiaceae) root tips derived from in vitro mutagenesis
}

\author{
Wee-Hiang ENG ${ }^{1}$, Wei-Seng $\mathrm{HO}^{1 *}$, Kwong-Hung $\mathrm{LING}^{2}$ \\ ${ }^{1}$ Universiti Malaysia Sarawak, Forest Genomics and Informatics Laboratory (fGiLab), Faculty of Resource Science and Technology, \\ 94300 KotaSamarahan, Sarawak, Malaysia; engweehiang@gmail.com; wsho@unimas.my (*corresponding author) \\ ${ }^{2}$ Sarawak Timber Association, Wisma STA, 26, Jalan Datuk Abang Abdul Rahim, 93450 Kuching, Sarawak, \\ Malaysia; khling68@gmail.com
}

\begin{abstract}
Chromosome count is the only direct way to determine the number of chromosomes of a species. This study is often considered trivial that seldom described and discussed in detail. Therefore, it is inevitable that the chromosome count protocol should be revised and revisited before it becomes obliterated. In the present study, we encountered challenges in obtaining a clear micrograph for the chromosome count of active mitotic cells of Neolamarckia cadamba (Roxb.) Bosser (Rubiaceae) root tips. Several obstacles were determined through micrograph observation, such as existing unwanted particles in cells, poor chromosome staining and chromosome clumping. To overcome these, root tip types, staining methodologies, squashing methods were among the factors assessed to obtain clear micrographs. The chromosome counts of $N$. cadamba under optimized procedure showed $2 n=44$ chromosomes. We also apply digital technology in chromosome counts, such as online databases and graphic software that are open source and freely accessible to the public. Only basic laboratory equipment and chemicals were used throughout the study, thus making this study economical and applicable in a basic laboratory. The availability of online digital software and databases provide open-source platforms that will ease the efforts in chromosome count.
\end{abstract}

Keywords: ImageJ; mitotic chromosomes; polyploid; Rubiaceae; single and double staining

\section{Introduction}

Neolamarckia cadamba (Roxb.) Bosser (Rubiaceae) is a large, deciduous and fast-growing tree species, and therefore guarantee early economic return within 8 to 10 years (Ho et al., 2014; Pang et al., 2015; Tchin et al., 2018 a,b). It is one of the best sources of raw material for the plywood industry, besides pulp, paper production and medicinal purposes. Phytochemicals can be extracted from different plants to determine its potential (Ianculov et al., 2005; Barbat et al., 2013; Bostan et al., 2013). Therefore, it is a viable option to improve this species by mutation. Improving conventional chromosome count protocol is fundamental in determining the success of mutagenesis through chromosome doubling in this study.

Received: 17 Jun 2021. Received in revised form: 25 Jul 2021. Accepted: 12 Aug 2021. Published online: 18 Aug 2021.

From Volume 13, Issue 1, 2021, Notulae Scientia Biologicae journal uses article numbers in place of the traditional method of continuous pagination through the volume. The journal will continue to appear quarterly, as before, with four annual numbers. 
Chromosome count is a direct, unambiguous and routine way of determining chromosome number in plant cells. This method is vital in plant systematics, taxonomy and breeding studies. In classical plant systematic study, chromosome count data are used to categorize plants and to identify relatedness between species in a family (Lee, 1979; Puangsomlee and Puff, 2001). In plant breeding, chromosome count is also used to detect the occurrence of polyploidy (Martin et al., 2019), double haploids (Kim et al., 2019) and sometimes interploids (de Alencar et al., 2020). Although chromosome count protocol was developed decades ago, it is still primarily conducted manually through sample preparation and microscopic observation. This protocol is often criticized as labour intensive, time-consuming and therefore challenging to obtain desirable micrographs (Ochatt et al., 2011). At the moment, total automation in chromosome count to make chromosome count faster is still unavailable. Chromosome count study is getting lesser attention lately due to the invention of flow cytometry (FCM) analysis. FCM has somehow eclipsed the importance of chromosome count in plant science as FCM is conducted digitally with minimum sample preparation. However, FCM is still unavailable in many laboratories due to its cost.

The availability of multiple online sources of data allows researchers to access the databases and counter reference chromosome counts from other studies to ascertain the validity of the assessments. Two recent articles (Bedini and Peruzzi, 2015; Rivero et al., 2019) discuss a list of online resources regarding chromosome count data of various plants. Nevertheless, chromosome count data obtained decades ago could be different from the present chromosome count data due to natural causes, such as geolocation of the samples obtained (Bedini and Peruzzi, 2015; Rice et al., 2019), polyploidy, amphiploidy, aneuploidy, haploidy (Sharma and Sen, 2019; Lavania, 2020). Erroneous chromosome counts can occur when the number of chromosomes is numerous and small (Huang, 2016). Some old chromosome count data were disputable in the family Rubiaceae because the researches were conducted many decades ago when microscopic technology was not advanced (Kiehn, 1995).

Chromosome count procedure is often simplified and generalized as a three-step procedure, namely pretreatment, fixation and staining (Maluszynska et al., 2003; Ochatt et al., 2011; Singh, 2016; Singh, 2017). This procedure provides generalized basic steps in sample preparation for chromosome count. However, the vast number of diverse plants in planta kingdom are varied in terms of cell size, the composition of cytoplasm, chromosome number and size, cell wall thickness and so forth. These variations render modification in steps difficult to undertake, such as the concentration of reagents, treatment durations and squashing methods to obtain an accurate result (de Alencar et al., 2020; Jiang et al., 2020). Most reagents and stains in chromosome count studies were developed many decades ago. Therefore, information on the origin, characteristics and reactions of these chemicals is not readily available in recent publications. So far, only Sharma and Sharma (1980) have published a huge repertoire of chromosome count chemicals with detailed information. Based on the details of the chemical reaction, chemical treatment can be modified accordingly to obtain the desired result.

In this article, we described the optimization and automation procedures for the chromosome counts in $N$. cadamba and ascertained that the previous colchicine induced mutation study was sufficient to induce polyploidy (Eng et al., 2021). Open-source platforms such as online databases and digital software were found to be helpful in polyploidization and cytogenetic studies.

\section{Materials and Methods}

\section{Root provenance}

The nodal segments from a single seedling were treated with different concentrations of colchicine $(0.1 \%, 0.3 \%, 0.5 \%)$ at different durations $(24 \mathrm{~h}, 48 \mathrm{~h})$. In this study, root tips from control and colchicine treated explants were used to determine the effects of colchicine on chromosome doubling of $N$. cadamba cells. Root tips of a cm in length each were excised from the plantlets derived from in vitro mutagenesis study (Eng 
et al., 2021) between 9.00 to 10.00 am and then cleaned with running tap water. Two types of root-tips were evaluated for suitability in chromosome count, namely: (a) young roots, 5-day-old root tips and (b) older root, 20-day-old root tips before proceeding to the next process.

\section{Pre-treatment and fixation}

The cleaned root tips were dipped in $0.002 \mathrm{M} 8$-hydroxyquinoline for $2 \mathrm{~h}$ at $4{ }^{\circ} \mathrm{C}$ then for another $2 \mathrm{~h}$ at room temperature $\left(25^{\circ} \mathrm{C}\right)$ and washed the pre-treated root tips three times with distilled water before fixation procedure. After the pre-treatment, the root tips were fixed in freshly prepared cold 3:1 Carnoy's solution (Ethanol 95\%: Acetic Acid; respectively) for $24 \mathrm{~h}$ at $4{ }^{\circ} \mathrm{C}$. The fixed root tips were then washed three times with distilled water before proceeding to the following.

\section{Staining}

The pre-treated and fixed root tips were first digested using $1 \mathrm{~N} \mathrm{HCl}$ for $15 \mathrm{~min}$ at $60{ }^{\circ} \mathrm{C}$ and then washed three times with distilled water. All the staining was conducted at room temperature, but the Feulgen stain was applied to the root tips under dark condition. The digested young root tips were stained and squashed in the following five ways:

a) aceto-orcein $1 \%$ for $15 \mathrm{~min}$ then squashed with a drop of aceto-orcein $1 \%$;

b) aceto-carmine $1 \%$ for 15 min then squashed with a drop of aceto-carmine $1 \%$ before the thumb squash;

c) Feulgen stain for 30 min then squashed with a drop of Feulgen before the thumb squash;

d) Feulgen stain for 30 min before squashed with a drop of aceto-orcein 1\%; and

e) Feulgen stain for 30 min before squashed with a drop of aceto-carmine $1 \%$.

\section{Observation under microscope}

LEICA DM500 compound light microscope was used to observe the chromosomes with 10x, 40x and 100x objective lens. Root cells were observed initially using the 10x objective lens to determine the location of the root tip where the root meristem cells are located. The cells are round in shape with bigger nuclei occupying most of the cytoplasm while the non-mitotic cells are elongated with smaller nuclei. After the location of root meristem cells was determined, the objective lens was changed to $40 \mathrm{x}$ to determine the location of the actively dividing cells with the nuclei in the pro-metaphase stage. Next, increase the power of the objective lens to $100 \mathrm{x}$ to select an ideal nucleus at the pro-metaphase stage with well-spread and visible chromosomes. Micrographs were captured using LEICA Application Suite (LAS EZ) and LEICA ICC50 HD camera.

\section{Counting chromosome using ImageJ}

ImageJ 1.52 software (open source) was used to crop and magnify the micrographs captured. This software can be downloaded for free from https://imagej.nih.gov/ij/. On the toolbar, choose "Multi-point" tool, and it was used as a counter to mark and label the stained chromosomes. The number of chromosomes will be shown at the window of "Multi-point" tool.

\section{Results and Discussion}

\section{Chromosome number, chromosome morphology and the mitosis mechanism of N. cadamba}

Under the optimized procedure in the chromosome count of active mitotic cells of $N$. cadamba root tips, the micrographs of both treated and untreated materials showed $2 n=44$ (Figure 1). The micrograph captured in this study also showed well-spread and visibly distinct chromosomes with a clear background in the nucleus. The stained chromosomes are small and without any discernible chromosome constrictions. Therefore, the shapes of the chromosomes appear roundish but cannot be determined in greater details. 


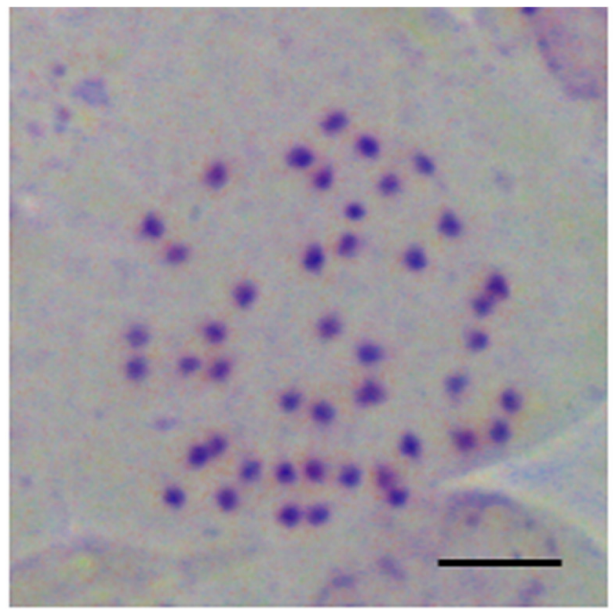

Figure 1. Chromosome spread of tetraploid cell observed under magnification of 100x, showed $N$. cadamba with 44 chromosomes $(\mathrm{Bar}=5 \mu \mathrm{m})$

The requirements to obtain well-spread and visibly distinct metaphase chromosomes with a clear background in the nucleus can be more favourably achieved by using 5-day-old root tips and double staining. Our chromosome count is in agreement with the chromosome count conducted previously using mitotic cells, which is $2 n=44$ (Kiehn and Lorence, 1996). Other studies in agreement with our chromosome count were using pollen - meiotic cells that showed 22 chromosomes or $n=22$ (Mehra and Bawa, 1969; Bedi et al., 1981; Puangsomlee and Puff, 2001). All the previous chromosome counts in $N$. cadamba stated that $N$. cadamba is a tetraploid plant. There was no dispute or deviation between chromosome counts published in between decades and researches carried out on different locations across vast geological distances. Chromosome counts were identical for samples from Thailand (Puangsomlee and Puff, 2001), China (Kiehn and Lorence, 1996), India (Mehra and Bawa, 1969; Bedi et al., 1981) and Malaysia. Our finding is that there is no variation in chromosome counts from different publications. According to Kiehn (1995), chromosomes number counts in the family Rubiaceae that deviates from published records should be treated with caution as it was counted decades ago. Errors in chromosome count might cause the deviation.

$N$. cadamba has small chromosomes, less than $1 \mu \mathrm{m}$ showing an almost spherical shape (Figure 1). Hence, the chromosome constrictions are not visible using the current method of sample preparation and the compound microscope. Without visible chromosome constriction, the shape of the chromosomes cannot be determined accurately, which makes karyotyping studies a challenge. Chromosomes without particular shape and pattern in all dimensions are termed as metacentric and symmetrical chromosomes, where the short chromosome's arms are equal in length and median kinetochore (Sharma and Sen, 2019). According to a study on karyo-morphology of Rubiaceae (Selveraj, 1987), chromosome less than $1 \mu \mathrm{m}$ in length is exceptionally small. The higher the number of chromosomes, the smaller the chromosomes, for example, bigger chromosomes in Coffea robusta $(2 n=22)$ versus smaller chromosomes in Coffea arabica $(2 n=44)$. Chromosomes of woody angiosperms are usually small, and there is little size difference between related species and genera (Sharma and Sen, 2019). However, chromosome size and morphology are of little taxonomic use in family Rubiaceae (Corréa and Forni-Martins, 2004).

Several phases in mitosis of $N$. cadamba root tip cells can be observed during the process of searching for cells in the pro-metaphase stage when the chromosomes can be observed and counted. The micrographs also showed different phases of mitosis (Figure $2 \mathrm{a}-\mathrm{f}$ ). The collection of micrographs provides an overview of the mitosis cycle of $N$ cadamba, thus helping the researcher to identify the phases of mitosis and understand the mechanism of mitosis. Of all the phases of mitosis observed, only pro-metaphase or early metaphase can provide distinctly clear and separately individual chromosomes, an ideal micrograph for counting chromosomes. 


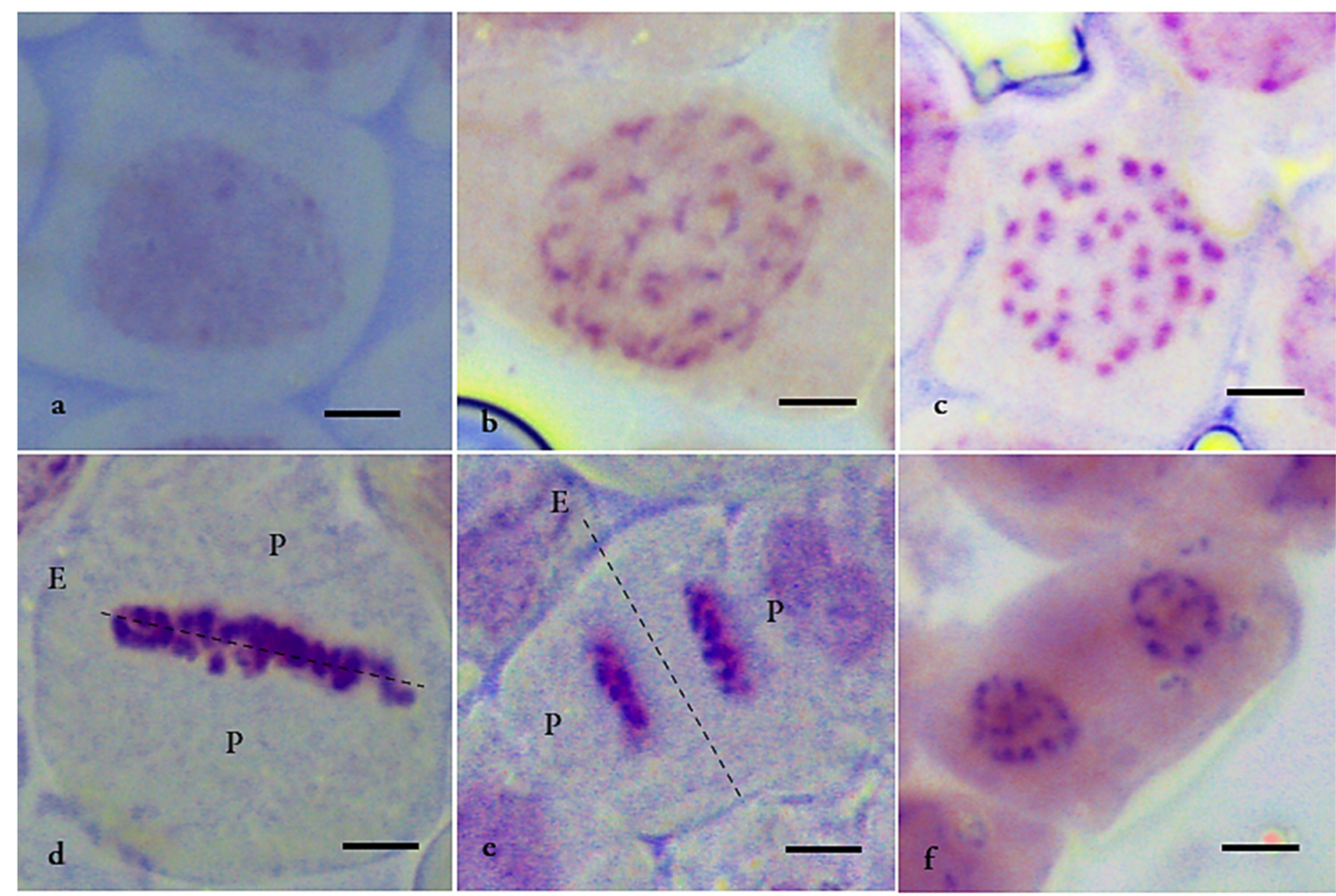

Figure 2. Different stages of division of tetraploid cell of $N$. cadamba, (a) interphase, (b) prophase, (c) prometaphase, $(\mathrm{d})$ metaphase, $(\mathrm{e})$ anaphase and $(\mathrm{f})$ telophase $(\mathrm{Bar}=5 \mu \mathrm{m})(\mathrm{P}=$ pole; $\mathrm{E}=$ equator $)$

It is generally accepted that most species in the Rubiaceae family that $N$. cadamba belongs to have a basic chromosome number $11(x=11)$. This basic chromosome number is still valid, in agreement with our study and many other studies in decades (Khoshoo et al. (1963); Lee (1979); Bedi et al. (1981); Kiehn (1986); Kiehn (1995); Corréa and Forni-Martins (2004); Kiehn (2010); Mehrvarz and Ghadim (2015)). Based on the most comprehensive chromosome number data compiled in 1979; 730 species in the Rubiaceae family were examined; 493 species have chromosome base number $x=11 ; 200$ species are polyploids at different levels of ploidy and 155 species are tetraploids with 44 chromosomes $(2 n=4 x=44)$ (Lee, 1979). Furthermore, tribe Naucleeae which $N$. cadamba also belongs, has chromosome base number $x=11$, which is either diploid $(2 x=$ 22) or tetraploid $(4 x=44)$ (Lee, 1979; Mathew and Philip, 1986).

\section{Chromosome count optimization}

Chromosome count is the conventional technique of ploidy level determination which is laborious and requires much time and effort to produce the desired result. This procedure has been practised since 1921, firstly by Belling J. but it is still widely used to determine the exact chromosome number of a sample. The main part of this chromosome count procedure practised nowadays has been derived from the old literature (Windham et al., 2020). However, to obtain the desired result, further modification of the steps may be required to suit the particular species as each species is different from the other in many respects, such as chromosome size, chromosome number, cell characteristics and cytoplasm composition.

An initial study must be undertaken to evaluate the more suitable age of the root tips to be used for chromosome count, namely 5-day-old root tip (Figure 3a) or 20-day-old root tip (Figure 3b). It was found that the 5-day-old root tip was better than the 20-day-old root tip. The younger root tip is thicker, softer and without root hairs. These characteristics make the chromosome count easier. Younger root tip, which is thicker, has more actively dividing cells, thereby increasing the chances of observing cells in pro-metaphase stage with good chromosomes spread. 


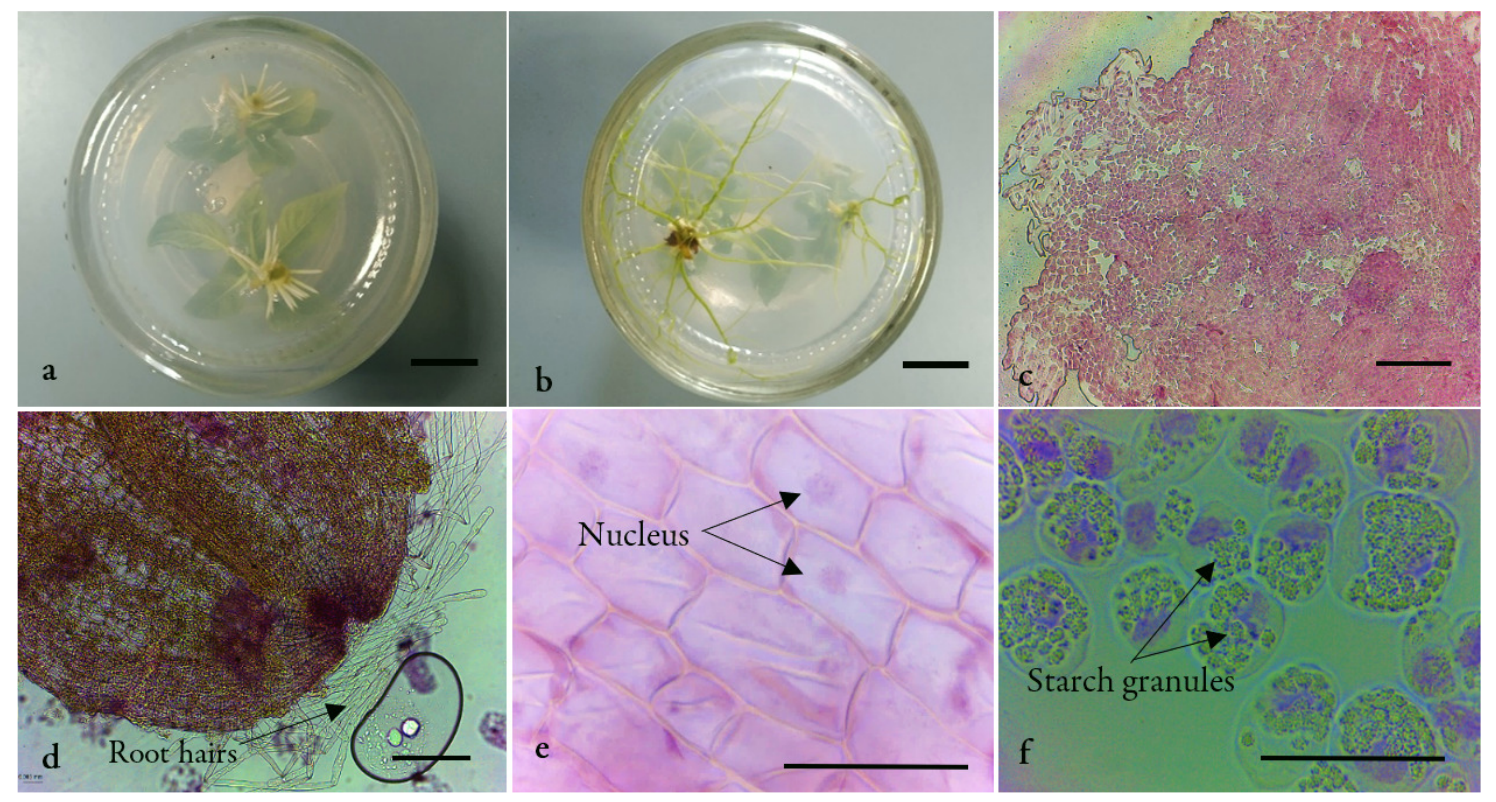

Figure 3. In vitro rooting and squashed root cells of $N$. cadamba. (a) 5-DO roots $(\mathrm{Bar}=1 \mathrm{~cm})$, (b) 20-DO roots $(\mathrm{Bar}=1 \mathrm{~cm}),(\mathrm{c})$ root tip with well-spread cells $(\mathrm{Bar}=0.2 \mathrm{~mm}),(\mathrm{d})$ root tip with root hairs without cell spread $(\mathrm{Bar}=0.2 \mathrm{~mm}),(\mathrm{e})$ non-mitotic cells with very small nuclei with thick cell walls and in angular shape $(\mathrm{Bar}=50 \mu \mathrm{m})$ and $(\mathrm{f})$ cells with starch granules $(\mathrm{Bar}=50 \mu \mathrm{m})$

Furthermore, the younger root tip, which is softer, makes squashing using a coverslip easier. After squashing, the root meristem cells would spread more evenly, thus avoiding the problem of overlapping cells (Figure 3c). Older root tip aged 20 days old and onwards is slender and tends to produce root hairs (Figure 3d), which reduces the visibility of the chromosomes and produces very little cell spread. In the root section further away from the older root tip, the cell walls are thick and the nuclei are much smaller in relation to the size of cytoplasm (Figure 3e). This indicates that the cells are not actively dividing.

In terms of cellular characteristics, cells in older root tips tend to have more particles than the root meristem cells. These particles are suspected to be starch grains (Figure 3f). The morphology of starch grains is species-specific (Matsushima, 2015). In the present study, the suspected starch grains are similar to starch grains of sweet potato and rice (Figure 3f) which are compound starch grains.

Often compound starch grains will break up when squashed, leading to spreading across the whole cell and making chromosome count impossible. Hence, younger root tips should be used to reduce the chance of obtaining cells with accumulated starch grains. In $N$. cadamba, non-mitotic cells accumulate starch grains that often create unwanted noises among chromosomes, thus making chromosome count impossible (Figure $3 \mathrm{f}$ ). Newly developed root cells have less accumulation of starch grains as time is needed to transport newly synthesized photosynthate from leaves to roots.

Starch grains in the root are insoluble, energy-dense and osmotically inert. Starch grains also serve as storage and will be remobilized when the photosynthesis process is inadequate to support the functions of the plant. (Pfiste and Zeeman, 2016). Both root tips and shoot tips are often used in chromosome count. In the case of $N$. cadamba, root tips are preferred because root tips are more non-destructive as roots are easily generable. Under in vitrocondition, roots can be formed easily without inflicting much harm to the root system of the plant. 
The solution of $0.002 \mathrm{mM}$ of 8-hydroxyquinoline has been used effectively to pre-treat root tips of plants with small chromosomes (Singh, 2017). It increases the cell plasm viscosity, preventing chromosomes from clumping together (Singh, 2017; Candan, 2013). Furthermore, this reagent serves as a fixative to a certain degree by coagulating proteins in the cell's organelles (Candan, 2013).

Three types of stains were evaluated to assess the most suitable stain or combination of stains for this study. These stains are Feulgen, aceto-orcein $1 \%$ and aceto-carmine $1 \%$. The stains were used either singly or in combination to obtain vividly stained chromosomes. During the staining process, it is essential to observe that root tips must be visible in magenta colour at the end of the staining, especially at the tips before proceeding to squash. If the root tips remained white even though the staining duration was extended, the sample should be discarded as no staining has taken place. This is vital to create a clear micrograph that shows vividly stained chromosomes in distinct contrast against the background. A clear micrograph will enable chromosome count easier. The choice of suitable stain types will be the result of several trial-and-error processes.

The micrographs of $N$. cadamba taken on root tip cells stained with either aceto-orcein 1\% (Figure 4a) or aceto-carmine $1 \%$ (Figure $4 \mathrm{~b}$ ) individually were grainy and not clear. These two stains could have caused the blurry background among the chromosomes. The cytoplasm around the chromosomes appeared to be partially stained especially when aceto-orcein $1 \%$ was used, leading to a blurry background. Feulgen stain produces a clearer micrograph with more countable chromosomes (Figure 4c). All the three stains, if used singly, are not able to stain every chromosome intensely and uniformly. They stain the chromosomes at a different intensity. Furthermore, the chromosome counted is always less than $2 n=44$ for $N$. cadamba. When a combination of two types of stains was used, that is either Feulgen + aceto-orcein 1\% (Figure 4d) or Feulgen + aceto-carmine $1 \%$ (Figure 4e), 44 clear and vividly stained chromosomes were visible in each $N$. cadamba tetraploid cell and likewise 88 chromosomes in octoploid N. cadamba 'Kestamas-19' cell. However, a combination of Feulgen + aceto-orcein $1 \%$ of stains produced better colour intensity and clarity of stained chromosomes. Therefore, a stain combination of Feulgen + aceto-orcein $1 \%$ is recommended for application in the staining chromosome of $N$. cadamba for this chromosome count.

Feulgen stain is a better stain than aceto-carmine $1 \%$ and aceto-orcine $1 \%$ for staining chromosomes of $N$. cadamba. This stain produces fairly vivid chromosomes but does not stain the cytoplasm around the chromosomes. Aceto-carmine $1 \%$ is the less favourable stain compared to Feulgen and aceto-orcein $1 \%$ as the former produces faintly stained $N$. cadamba chromosomes. In our study on $N$. cadamba, aceto-orcein $1 \%$ produce intense colour to the chromosomes, leading to partially stained cytoplasm. Aceto-orcein and aceto carmine are often used interchangeably if one of them does not stain effectively. Acetic acid $45 \%$ is used to dissolve the carmine and orcein powder. Acetic acid (45\%) also ensures fast penetrative effects for stains, and it acts as a fixative to the chromosomes (Sharma and Sharma, 1980). There are many stains available for chromosome count study. Evaluating these stains should be conducted either by single stain application or combination of stains application to achieve good results. Apart from selecting the type(s) of stains used, other parameters can also be assessed, such as the stain concentration and staining duration. 


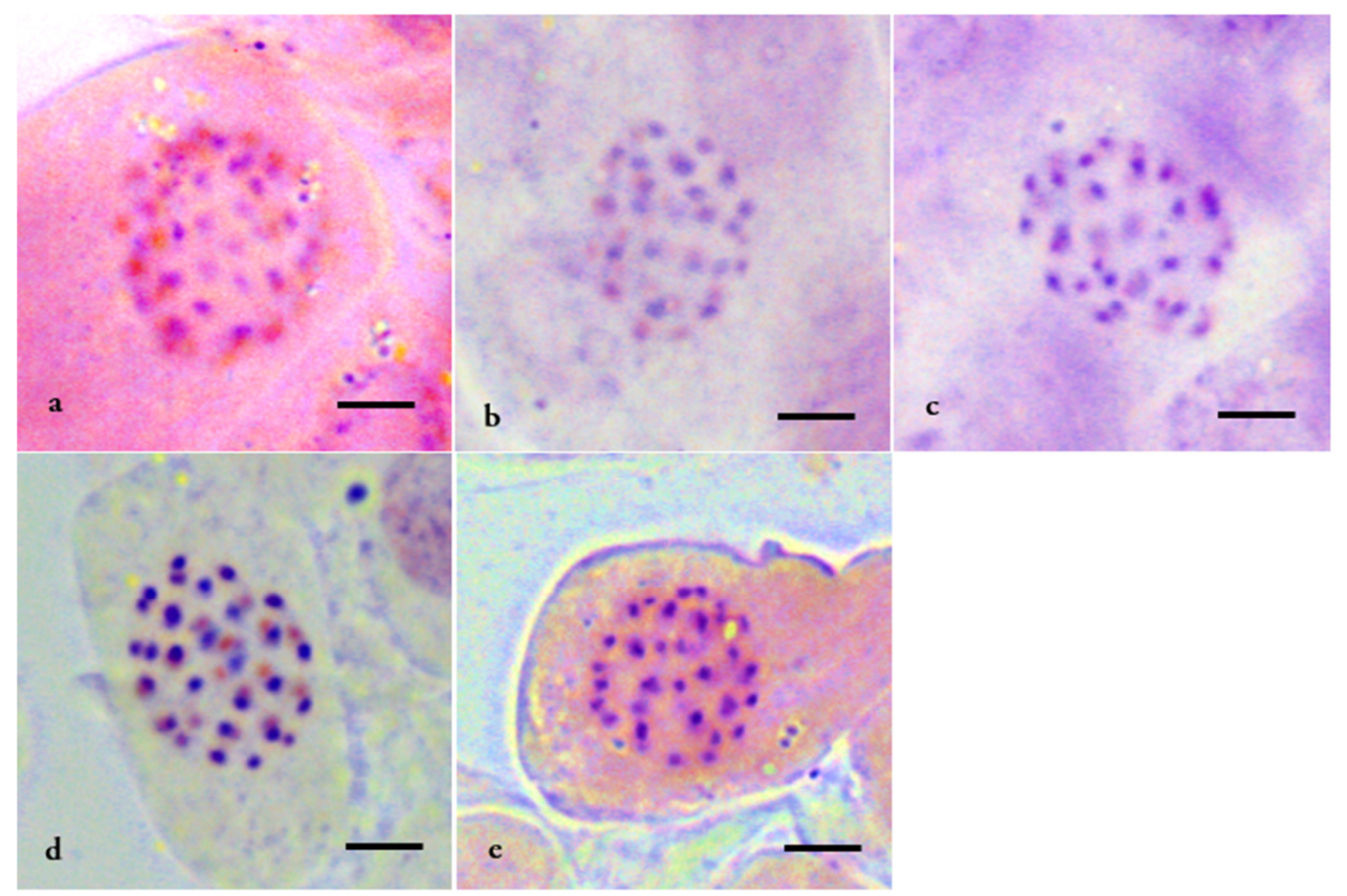

Figure 4. Effect of single and combination stain(s) on chromosomes of N. cadamba. (a) aceto-orcein 1\%, (b) aceto-carmine 1\%, (c) Feulgen, (d) Feulgen + aceto-orcein 1\% and (e) Feulgen + aceto-carmine $1 \%$ $(\mathrm{Bar}=5 \mu \mathrm{m})$

A well-stained root tip was mounted on a slide and squashed to release a monolayer of root cells, revealing stained chromosomes before observation under the microscope. Thumb squash using a coverslip is a common practice to spread the cells and chromosomes on the slide. In our experience, this method does not exert sufficient force to spread the cells and chromosomes evenly for viewing under the microscope (Figure 5ac). Inadequate force of thumb squash method on the root tip of N. cadamba causes cells to overlap each other and creates multiple layers of cells on the slide. The chromosomes in $N$. cadamba also tend to clump together and overlap with each other. These factors make the counting of chromosome impossible. In order to overcome these obstacles, a metal bar was introduced to initially squash the root tip directly on a slide with a drop of selected stain before the thumb squash with a coverslip. By double squashing the root tip as mentioned, the chromosomes in the cell can be more evenly spread to make chromosome count easier. The root tip cells will be well-spread so that there are many choices to select the best cell with perfectly spread chromosomes for viewing and counting under the microscope. Squashing techniques are rarely described and discussed in the published articles that mention chromosome count. To achieve a well-spread chromosome scenario, the researchers may need to modify the existing methods or invent new squashing strategies to suit their samples.

\section{Automation in chromosome count}

Micrograph with well-spread cells and vividly stained chromosomes will be used to determine the number of chromosomes per nucleus using the ImageJ program (Figure 6a). There are many tools available in ImageJ program that is useful in scientific image processing. "Multipoint tool" can be used as a marker and counter to the chromosomes on micrograph. Chromosomes can be marked by selecting "Multipoint tool" and positioning the cursor on the chromosomes followed by right-clicking (Figure 6b). Then, by choosing "label", all marked chromosomes will be labelled with a number that will add up to the total chromosome number (Figure 6c). The labelled micrograph can be saved by using "Plugins" - "Utilities" - "Capture image". This 
process prevents the researcher from wrongly counting the chromosomes, especially when the chromosomes are numerous and small, like $N$. cadamba. Counting chromosomes manually can be laborious and prone to error.

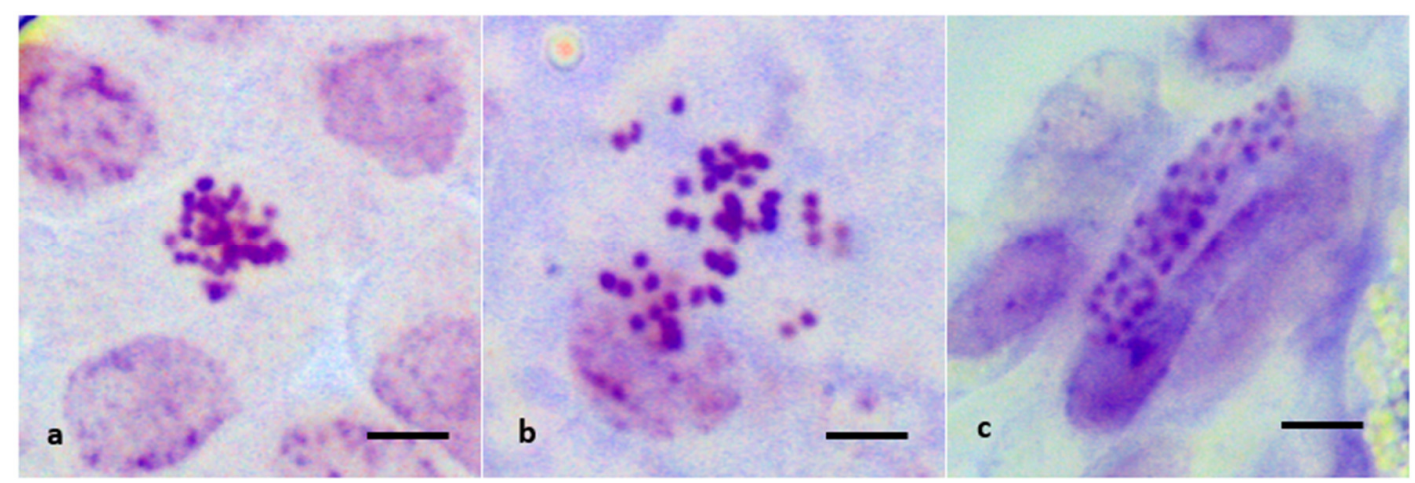

Figure 5. Squashed cells of $N$. cadamba. (a) inadequately squashed cells - chromosome clumping, (b) unevenly squashed cells - overlapped cells and (c) poorly squashed cells - skidded squash $(\mathrm{Bar}=5 \mu \mathrm{m})$

In this study, ImageJ was used to analyze micrographs obtained during the chromosome count study. These include micrograph cropping and chromosomes counting in the selected cell. We used a semi-automated approach in chromosome count with the help of ImageJ. Selection of stained chromosomes was made manually with the assistance of ImageJ by clicking on the stained chromosomes with the purpose to mark and count the chromosomes on the micrograph captured by the digital camera. ImageJ was used to select stained chromosomes manually on the monitor screen. The number of chromosomes will be summed up automatically at the end of chromosome selection by such selecting. Selecting manually by the researcher will prevent the inclusion of wrong particles that are not chromosomes in the counting.

$N$. cadamba cells are rich in starch grains, as evident in this study. Studies on members of the Rubiaceae family also showed similar evidence (Kiehn, 1995). These Rubiaceae plant cells produce a large number of particles that are trapped in the plant cell walls. Good sample preparation for chromosome count should have clear cytoplasm and free from particles other than the chromosomes. The presence of these particles is a major challenge when using ImageJ as a total automated procedure without human intervention to count the chromosomes in $N$. cadamba. Total automation in chromosome count is still far from perfect as errors and variations in chromosome number exist even within the same species (Gujendran and Rodriguex, 2004; Midin et al., 2018).

Two chromosome count studies utilized computer software to automatically count the chromosomes on micrographs captured by an electronic camera were reported (Gujendran and Rodriguex, 2004; Midin et al., 2018). This method uses an image thresholding technique to calibrate the micrograph to identify individual chromosomes, separate overlapped or clumped chromosomes and sharpen the images. ImageJ software was used to automatically determine chromosome number yielding a range of different chromosome numbers of a species (Midin et al., 2018). However, the mean number of chromosomes was used to determine the chromosome number of the species. In another study, automation of the chromosome count of human cells resulted in 6\% error rate as known somatic human cell has 46 chromosomes (Gujendran and Rodriguex, 2004). Automation in chromosome count requires optimization in slide preparation, which is tedious, especially when plant material is examined. The success and accuracy of the automation techniques used would largely depend on the quality of sample preparation that should minimize the occurrence of objects other than chromosomes (Gujendran and Rodriguex, 2004; Midin et al., 2018). 


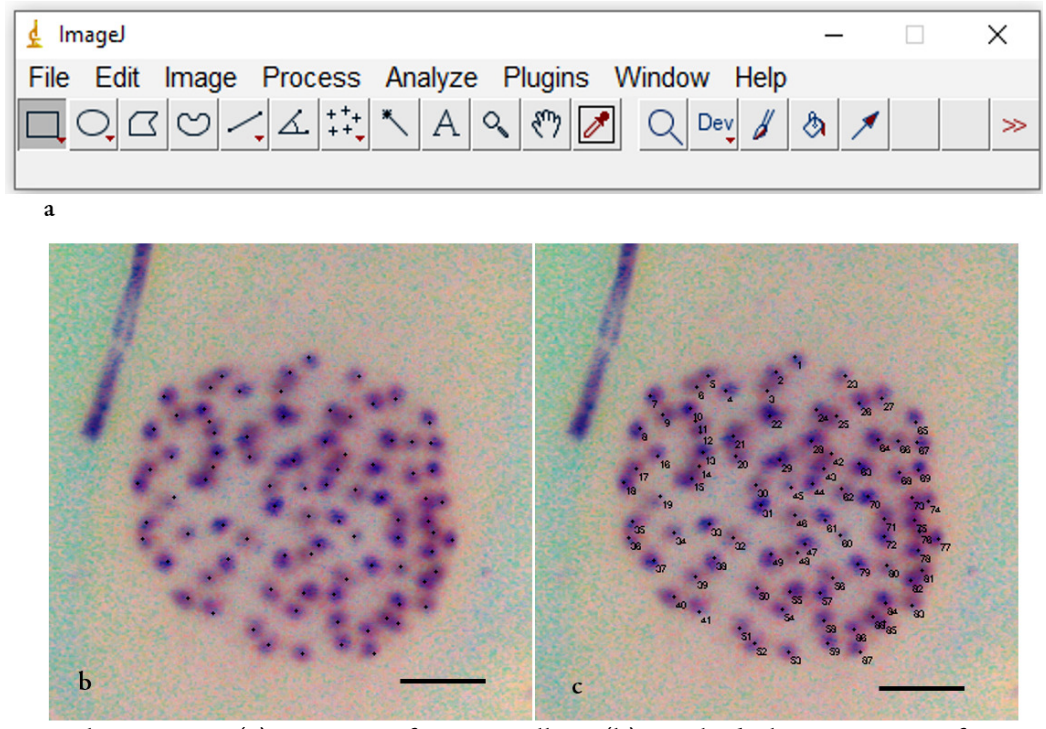

Figure 6. Digital counting: (a) ImageJ software toolbar, (b) marked chromosomes of octoploid of $N$. cadamba 'Kestamas-19' cell $(\mathrm{Bar}=1 \mu \mathrm{m})$ and $(\mathrm{c})$ numbered chromosomes of octoploid of $N$. cadamba 'Kestamas-19' cell $(\mathrm{Bar}=5 \mu \mathrm{m})$

\section{Online databases that are important to chromosome count}

The current online databases, although not exhaustive, help the researcher to cross-refer and obtain data regarding taxonomy (Table 1), ploidy level and chromosome count of plants (Table 2). There is no single database that provides all the required data. However, a combination of databases may be helpful. These databases are built serially over time based on researches done by different researchers. The database eases the researcher's effort to obtain the data as some of the researches were done decades ago, and their publications are not readily available online now. To obtain these data, knowing the taxonomy and phylogeny of the species and related species is essential (Table 1). Furthermore, many plant species have more than one name, either Latin name or synonym, and have older names. Knowing these names will increase the success rate of online data searching for chromosome count (Table 2).

Table 1. Online databases for taxonomic classifications in plants

\begin{tabular}{|c|c|c|}
\hline Organization & Website & Information provided \\
\hline $\begin{array}{l}\text { Integrated Taxonomic } \\
\text { Information System }\end{array}$ & https://www.itis.gov & $\begin{array}{c}\text { Taxonomy hierarchy and } \\
\text { nomenclature }\end{array}$ \\
\hline Plant Genera, Illustration & http://www.plantgenera.org & $\begin{array}{c}\text { Taxonomy hierarchy, nomenclature } \\
\text { and Illustration }\end{array}$ \\
\hline $\begin{array}{l}\text { United States Department of } \\
\text { Agriculture (USDA) }\end{array}$ & https://plants.usda.gov/home & $\begin{array}{c}\text { Taxonomy hierarchy, nomenclature } \\
\text { and distribution in USA }\end{array}$ \\
\hline The Plant List & http://www.theplantlist.org & Nomenclatural and scientific names \\
\hline $\begin{array}{l}\text { International Plant Names } \\
\text { Index (IPNI) }\end{array}$ & https://www.ipni.org & Nomenclature and scientific names \\
\hline $\begin{array}{l}\text { Biodiversity Heritage Library } \\
(\mathrm{BHL})\end{array}$ & https://www.biodiversitylibrary.org & $\begin{array}{c}\text { Digital library for classical } \\
\text { biodiversity literature and archives }\end{array}$ \\
\hline
\end{tabular}


Table 2. Online databases for chromosome numbers in plants

\begin{tabular}{|l|c|c|}
\hline \multicolumn{1}{|c|}{ Organization } & Website & Information provided \\
\hline Chromosome Counts Database & http://ccdb.tau.ac.il/ & Plants from different families \\
\hline Index to plant CNs & http://www.tropicos.org/Project/IPCN & Plant from worldwide \\
\hline Prota4U & www.prota4u.org/ & Tropical African plants \\
\hline Karyological database & https://www.chromosomes.sav.sk & $\begin{array}{c}\text { Ferns and flowering plants of } \\
\text { Slovakia }\end{array}$ \\
\hline Online plant CN databases & $\begin{array}{c}\text { http://www.bio.uni- } \\
\text { bayreuth.de/planta2/research/Aschrom/A } \\
\text { SCHROM.pdf }\end{array}$ & $\begin{array}{c}\text { Plants in Asclepiadoideae, } \\
\text { Periplocoideae, and Apocynaceae }\end{array}$ \\
\hline
\end{tabular}

Online databases for taxonomic classification in plants

The detailed taxonomy of $N$. cadamba has rarely been described in recent studies. $N$. cadamba belongs to subfamily - Cinchonoideae, tribes - Naucleeae and Subtribes - Neolamarckiinae. Comprehensive data of chromosome counts and taxonomy were combined to form a cytotaxonomy study of the family. Usually, members of tribes have the same basic chromosome number $(\mathrm{x})$ and ploidy level. This relationship helps provide some clue on chromosome number or ploidy level of the species that are yet to be determined.

They are many synonymous names of Neolamarckia cadamba (Roxb.) (Bosser, 1984), namely, Cephalanthus chinensis Lam. Encycl. (1785); Nauclea cadamba Roxb. (1824); Anthocephalus indicus A. Rich. (1834); Anthocephalus moridaefolius Korth. (1842); Anthocephalus chinensis (Lam.) A. Rich ex. Walp. Repert (1843); Anthocephalus cadamba (Roxb.) Miq. (1856) and Sarcopcephalus cadamba (Roxb.) Kurz. (1877). Many old references are difficult to find in libraries and online databases. The origin of these names can be traced using online resources provided by the Biodiversity Heritage Library (Table 1). These references are often scanned and transformed into digital books for the public. Knowing synonymous names of a species would make taxonomic and cytogenetics data searching less laborious and painstaking.

\section{Online databases for chromosome number in plants}

When searching for the chromosome count of a species, different synonymous names should be searched to obtain chromosome counts from different sources (Table 2). This will make the data obtained more reliable. Different articles may use different names in $N$. cadamba chromosome count study, such as Neolamarckia cadamba (Puangsomlee and Puff, 2001); Anthocephalus cadamba (Mehra and Bawa, 1969; Bedi et al., 1981) and Anthocephalus chinensis (Kiehn and Lorence, 1996). N. cadamba should be used universally until a new name is given. $N$. cadamba is the newest name given to this plant since 1984 . Older names should be avoided as it will reduce the visibility of the findings to the community who are conducting the researches.

\section{Conclusions}

This study has verified that the chromosome number of $N$. cadamba is 44 . The chromosomes are small and roundish. This study is also in agreement with the basic number of chromosomes $(x=11)$ in the family Rubiaceae. Different phases of mitosis from active mitotic cells of the root tip of $N$. cadamba were captured and compared. Only cells at early metaphase or pro-metaphase can be used for chromosome count study due to condensed or coiled chromosome structure. In the N. cadamba chromosome count optimization study, several factors were found to affect the micrograph used for chromosome count. These include very small chromosomes, chromosome clumping, poor chromosome staining, occurrence of starch granules and root hairs. Younger root tips (5-day old), double stains (Feulgen then aceto-orcein) and double squashes (metal bar then thumb) were found to be the key to well-stained, spread and clear micrograph. We also utilized the tools 
in ImageJ to help in facilitating the counting of chromosomes that were numerous. Several databases were found to be helpful in the study of polyploidization and cytogenetics.

\section{Authors' Contributions}

Eng, WH and Ho, WS designed the research project. Eng, WH performed the experiments and analyzed data. Eng, WH and Ho, WS wrote the manuscript. Ho, WS and Ling, KH modified the manuscript. All authors read and endorsed the final manuscript.

\section{Acknowledgements}

This study was supported by the funding from the Sarawak Timber Association (STA) to University Malaysia Sarawak (Grant No. GL(F07)/06/2013/STA-UNIMAS(06) and GL/F07/STA01/2019). The authors would like to acknowledge WTK for providing the plant materials for this research project. The Ministry of Education Malaysia $(\mathrm{MoE})$ is also acknowledged for granting financial assistance to the first author.

\section{Conflict of Interests}

The authors declare that there are no conflicts of interest related to this article.

\section{References}

Barbat C, Rodino S, Petrache P, Butu M, Butnariu M (2013). Microencapsulation of the allelochemical compounds and study of their release from different products. Digest Journal of Nanomaterials and Biostructures 8(3):945-953. https://www.chalcogen.ro/945_Butu.pdf

Bedi YS, Bir SS, Gill BS (1981). Cytopalynology of woody taxa of family Rubiaceae from North and Central India. $\begin{array}{lllll}\text { Proceeding Indian } & \text { Natural } & \text { Science } & \text { Academy } & \text { B47(6):708-715. }\end{array}$ https://insa.nic.in/writereaddata/UpLoadedFiles/PINSA/Vol47B_1981_5_Art16.pdf

Bedini G, Peruzzi L (2015). A comparison of plant chromosome number variation among Corsica, Sardinia and Sicily, the three largest Mediterranean islands. Caryologia 68(4):289-293. https://doi.org/10.1080/00087114.2015.1109932

Bosser J (1984). Bulletin du Muséum National d'Histoire Naturelle Section B, Adansonia, botanique, phytochimie. Muséum, Paris. https://www.biodiversitylibrary.org/bibliography/13855

Bostan C, Butnariu M, Butu M, Ortan A, Butu A, Rodino S, Parvu C (2013). Allelopathic effect of Festuca rubra on perennial grasses. Romanian Biotechnological Letters 18(2):8190-8196. https://erepository.org/rbl/vol.18/iss.2/14.pdf

Candan F (2013). Some observations on plant karyology and investigation methods. Current Protocol Biology Research 217-55. https://doi.org/10.5772/56081

Corréa AM, Forni-Martins ER (2004). Chromosomal studies of species of Rubiaceae (A. L. de Jussieu) from the Brazilian cerrado. Caryologia 57(3):250-258. https://doi.org/10.1080/00087114.2004.10589400

de Alencar, LD, Azevedo P, Latado RR (2020). Mothers' command: phenotypes changes resulting from reciprocal interploidy crosses. Euphytica 216:21. https://doi.org/10.1007/s10681-020-2557-4

Eng WH, Ho WS, Ling KH (2021). Effects of colchicine treatment on morphological variations of Neolamarckia cadamba. International Journal of Agricultural Technology 17(1):47-66. http://www.ijataatsea.com/past_v17_n1.html 
Gujendran V, Rodriguez JJ (2004). Chromosome counting via digital image analysis. International Conference on Image Processing 2929-2932. https://doi.org/10.1109/ICIP.2004.1421726

Ho WS, Pang SL, Julaihi A (2014). Identification and analysis of expressed sequence tags present in xylem tissues of kelampayan (Neolamarckia cadamba (Roxb.) Bosser). Physiology and Molecular Biology - Plants 20(3):393397. https://doi.org/10.1007/s12298-014-0230-X

Huang $\mathrm{H}$ (2016). Systematics and genetic variation of Actinidia. Academic Press, United States. https://doi.org/10.1016/B978-0-12-803066-0.00001-0

Ianculov I, Palicica R, Butnariu M, Dumbrava D, Gergen I (2005). Achieving the crystalline state of chlorophyll of the Fir-tree (Abies alba) and the pine (Pinus ylvestris). Revista de Chimie 56(4):441-443. https://adastra.ro/2016/05/05/the-obtaining-of-chlorophyll-in-crystalline-form-from-fir-needles-abies-alba-and-frompine-needles-pinus-silvestris/

Jiang Y, Liu S, Hu J, He G, Liu Y, Chen X, ... Gao S (2020). Polyploidization of Plumbago auriculata Lam. in vitro and its characterization including cold tolerance. Plant Cell, Tissue and Organ Culture 140:315-325. https://doi.org/10.1007/s11240-019-01729-W

Khoshoo TN, Sc FA, Bhatia SK (1963). Cytology of some Rubiaceae of the North-western Himalayas. Proceedings of the Indian Academy of Sciences 58(B):36-44. https://doi.org/10.1007/BF03052070

Kiehn M (1986). Karyosystematic studies on Rubiaceae: Chromosome counts from Sri Lanka. Plant Systematics and Evolution 154:213-23. https://doi.org/10.1007/BF00990124

Kiehn M (1995). Chromosome survey of the Rubiaceae. Annals of the Missouri Botanical Garden 82(3):398-408. https://doi.org/10.2307/2399890

Kiehn M (2010). Chromosomes of neotropical Rubiaceae. I: Rubioideae. Annals of the Missouri Botanical Garden 97(1):91-105. https://doi.org/10.3417/2007115

Kiehn M, Lorence DH (1996). Chromosome counts on Angiosperms cultivated at the National Tropical Botanical Garden, Kauai, Hawaii. Pacific Science 50(3):317-323. http://hdl.handle.net/10125/2903

Kim JS, Seo MS, Moon MS, Won SY, Kwon SJ (2019). Insight on doubled haploid production with an amphidiploid species 'Dolsangat' in Brassica juncea. Korean Journal Breeding Science 51(4):341-350. https://doi.org/10.9787/KJBS.2019.51.4.341

Lavania UC (2020). Plant speciation and polyploidy: in habitat divergence and environmental perspective. Nucleus 63:15. https://doi.org/10.1007/s13237-020-00311-6

Lee YS (1979). Remarks on chromosome number in Rubiaceae. Korean Journal of Plant Taxon 9(1):57-66. https://doi.org/10.11110/kjpt.1979.9.1.057

Maluszynska J (2003). Cytogenetics test for ploidy level analyse-chromosome counting. In: Maluszynski M, Kasha KJ, Forster BP, Szarejko I (Eds). Doubled haploid production in crop plants. Springer, Netherland pp 391-395. https://doi.org/10.1007/978-94-017-1293-4

Martin C, Viruel MA, Lora J, Hormaza JI (2019). Polyploidy in fruit tree crops of the Genus Annona (Annonaceae). Frontiers in Plant Science 10:99. https://doi.org/10.3389/fpls.2019.00099

Mathew PM, Philip O (1986). The distribution and systematic significance of pollen nuclear number in the Rubiaceae. Cytologia 51:117-124. https://doi.org/10.1508/cytologia.51.117

Matsushima R (2015). Morphological variations of starch grains. In: Nakamura Y (Ed). Starch. Springer, Japan pp $425-$ 441. https://doi.org/10.1007/978-4-431-55495-0_13

Mehra PN, Bawa KS (1969). Chromosomal evolution in tropical hardwoods. Evolution 23(3):466-481. https://doi.org/10.2307/2406701

Mehrvarz SS, Ghadim SM (2015). Chromosome counts of some species of the genus Galium (Rubiaceae) from Iran. Feddes Repertorium 126:31-36. https://doi.org/10.1002/fedr.201400026

Midin MR, Nordin MS, Madon M, Saleh MN, Goh H, Noor NM (2018). Determination of the chromosome number and genome size of Garcinia mangostana L. via cytogenetics, flow cytometry and k-mer analyses. Caryologia 1017:1-10. https://doi.org/10.1080/00087114.2017.1403762

Ochatt SJ, Patat-Ochatt EM, Moessner A (2011). Ploidy level determination within the context of in vitro breeding. Plant Cell, Tissue and Organ Culture 104:329-341. https://doi.org/10.1007/s11240-011-9918-6

Pang SL, Ho WS, Mat-Isa MN, Julaihi A (2015). Gene discovery in the developing xylem tissue of a tropical timber tree species: Neolamarckia cadamba (Roxb.) Bosser (Kelampayan). Tree Genetics and Genomes 11:47. https://doi.org/10.1007/s11295-015-0873-y 
Pfister B, Zeeman SC (2016). Formation of starch in plant cells. Cellular and Molecular Life Sciences 73:2781-807. https://doi.org/10.1007/s00018-016-2250

Puangsomlee P, Puff C (2001). Chromosome numbers of Thai Rubiaceae. Nordic Journal of Botany 21(2):165-176. https://doi.org/10.1111/j.1756-1051.2001.tb01354.x

Rice A, Šmarda P, Novosolov M, Drori M, Glick L, Sabath N, Meiri S, Belmaker J, Mayrose I (2019). The global biogeography of polyploid plants. Nature Ecology and Evolution 3:265-273. https://doi.org/10.1038/s41559018-0787-9

Rivero R, Emily B, Sessa EB, Zenil-Ferguson R (2019). EyeChrom and CCDBcurator: Visualizing chromosome count data from plants. Application in Plant Sciences 7(1):e1207. https://doi.org/10.1002/aps3.1207

Selvaraj R (1987). Karyomorphological studies in South Indian Rubiaceae. Cytologia 52:343-56. https://doi.org/10.1508/cytologia.52.343

Sharma A, Sen S (2019). Chromosome botany. CRC Press, Boca Raton. https://doi.org/10.1201/9780429187612

Sharma AK, Sharma A (1980). Chromosome techniques theory and practice. Butterworth \& Co. Ltd., United Kingdom. https://doi.org/10.1016/C2013-0-01036-5

Singh RJ (2016). Plant cytogenetics. CRC Press, USA. https://doi.org/10.1201/9781315374611

Singh RJ (2017). Practical manual on plant cytogenetics. CRC Press, Boca Raton. https://doi.org/10.4324/9781351228268

Tchin BL, Ho WS, Pang SL (2018a). Isolation and characterisation of cinnamate 4-hydroxylase ( $C 4 H$ ) gene controlling the early stage of phenylpropanoid biosynthetic pathway in developing xylem tissues of kelampayan (Neolamarckia cadamba, Rubiaceae). Asian Journal of Agriculture and Biology 6(2):278-286. https://www.asianjab.com/wp-content/uploads/2018/06/26.-OK_Isolation-and-in-silico-characterizationof-cinnamate-4-hydroxylase-c4h-gene-controlling-the-earlyl.pdf

Tchin BL, Ho WS, Pang SL (2018b). Isolation and in silico characterization of full-length cinnamyl alcohol dehydrogenase gene involved in lignin biosynthesis in Neolamarckia cadamba. Journal of Applied Biology and Biotechnology 6(2):1-5. http://doi.org/10.7324/JABB.2018.60201

Windham MD, Pryer KM, Poindexter DB, Li F, Rothfels CJ, Beck JB (2020). A step-by-step protocol for meiotic chromosome counts in flowering plants: A powerful and economical technique revisited. Applications in Plant Sciences 8(4):e11342. https://doi.org/10.1002/aps3.11342

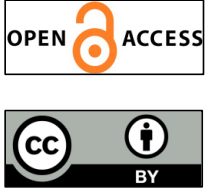

The journal offers free, immediate, and unrestricted access to peer-reviewed research and scholarly work. Users are allowed to read, download, copy, distribute, print, search, or link to the full texts of the articles, or use them for any other lawful purpose, without asking prior permission from the publisher or the author.

License - Articles published in Notulae Scientia Biologicae are Open-Access, distributed under the terms and conditions of the Creative Commons Attribution (CC BY 4.0) License.

(c) Articles by the authors; SHST, Cluj-Napoca, Romania. The journal allows the author(s) to hold the copyright/to retain publishing rights without restriction. 